\title{
Chlorophyll $a$ fluorescence transient as an indicator of active and inactive Photosystem II in thylakoid membranes
}

\author{
J. Cao and Govindjee \\ Departments of Physiology and Biophysics and Plant Biology, University of Illinois at Urbana-Champaign. \\ Urbana, IL (U.S.A.)
}

(Received 20 June 1989)

Key words: Chlorophyll a fluorescence; Inactive Photosystem II center; Photosystem II; Quinone; Heat stress; (Spinach); (Soybean)

Upon illumination, a dark-adapted photosynthetic sample shows time-dependent changes in chlorophyll (Ch) $a$ nuorescence yield, known as the Kautsky phenomenon or the OIDPS transient. Based on the differential effects of electron acceptors such as 2,5-dimethyl-p-benzoquinone (DMQ) and 2,6-dichloro-p-benzoquinone (DCBQ) on Chl a fluorescence transients of spinach thylakoids, we suggest that the OID phase reflects the reduction of the electron acceptor $Q_{A}$ to $Q_{A}^{-}$in the inactive PS II (see Graan, T. and Ort, D. (1986) Biochim. Biophys. Acta 852, 320-330 [14]). In spinach thylakoids, heat-induced increase of the $\mathrm{Chl} a$ fluorescence yield is also differentially sensitive to the addition of DMQ and DCBQ suggesting that this increase is mainly on the ' $l$ ' level, and thus heating is suggested to convert active PS II to inactive PS II centers. The kinetics of decay of $Q_{A}^{-}$, calculated from variable Chl $a$ fluorescence, was analyzed into three exponential components (365-395 $\mu \mathrm{s} ; 6-7 \mathrm{~ms}$; and 1.4-1.7 s). In heated samples, the decay rate of variable $\mathrm{Chl} a$ fluorescence is slower than the normal back-reaction rate; there is a preponderance of the slow component that may be due, partly, to the inactive centers undergoing slow back reaction between $Q_{A}^{-}$and the $S_{2}$ state of the oxygen-evolving complex.

\section{Introduction}

Kautsky and Hirsch [1] observed changes in the time-course of chlorophyll $a(\mathrm{Chl} a)$ fluorescence when a dark-adapted photosynthetic sample was illuminated with light. Since that time $\mathrm{Chl} a$ fluorescence transient (known as the Kautsky phenomenon) has been used as a non-destructive, sensitive tool for monitoring various processes in photosynthesis [2-5]. However, this application has been fraught with complexities. For example, even the nature and the meaning of the fast OIPD (see below for explanation of symbols) fluorescence changes have been debated, leading to contradictions in the literature [6].

\footnotetext{
Abbreviations: Chl $a$, chlorophyll $a$; DCBQ, 2,6 dichloro-p-benzoquinone; DCMU, 3-(3,4-dichlorophenyl)-1,1-dimethylurea; DMQ, 2,5-dimethyl-p-benzoquinone; Mes, 2-[ $N$-morpholino\}ethanesulfonic acid; PS I, Photosystem I; PS II, Photosystem II; $Q_{\wedge}$, bound plastoquinone, an electron acceptor of Photosystem II; $Q_{B}$, another bound plastoquinone, a two-electron acceptor of Photosystem II.
}

Correspondence: Govindjee, Department of Plant Biology, University of Illinois at Urbana-Champaign, 289 Morrill Hall, 505 South Goodwin Avenue, Urbana, IL 61801, U.S.A.
The ' $O$ ' (for origin) level (also called $F_{0}$ ), the so-called constant fluorescence, is the level obtained instanteously (within $1 \mathrm{~ns}$ ) of illumination, when all $\mathrm{Q}_{\mathrm{A}}$ is in the oxidized state; it is the minimum fluorescence in Photosystem II (PS II) membranes. In a model in which excitation can travel randomly among all the pigments ('lake model') (however, see Eqn. 2):

$F_{0}=F_{\text {minimum }}=\phi_{f \text { minimum }}\left(I_{\mathrm{abs}}\right)=\frac{K_{\mathrm{f}}}{K_{\mathrm{f}}+K_{\mathrm{h}}+K_{\mathrm{t}}+K_{\mathrm{p}}\left[\mathrm{Q}_{\mathrm{A}}\right]}\left(I_{\mathrm{abs}}\right)$

where $\phi_{f \text { minimum }}=$ minimum quantum yield of fluorescence, $I_{\text {abs }}=$ number of photons absorbed, $K_{\mathrm{f}}=$ rate constant of fluorescence, $K_{\mathrm{h}}=$ rate constant of radiationless (heat) loss, $K_{\mathrm{l}}=$ rate constant of excitation energy transfer, $K_{\mathrm{p}}=$ rate constant of photochemistry, and $\left[Q_{A}\right]$, the concentration of the electron acceptor bound plastoquinone $Q_{A}$ of PS II; maximum $\left[Q_{A}\right]$ is taken as 1 . In thylakoid membranes, the measured $F_{0}$ at room temperature also includes a minor (about 20\%) contribution from PS I Chl $a$ fluorescence [7]. The initial fluorescence level, measured by most instruments, is called $F_{\mathrm{i}}$ (for $F_{\text {initial }}$ ) unless it is proven to be $F_{0}$. The major criterion for $F_{\mathrm{i}}$ to be $F_{0}$ is the indepen- 
dence of its yield ( $\phi_{f \text { minimum }}=F_{0} / I_{\text {abs }}$ ) on exciting light intensity and the addition of electron acceptors [8]. Under these conditions, changes in $F_{0}$ can be ascribed to changes in the heat loss $\left(K_{\mathrm{h}}\right)$ or in excitation energy transfer $\left(K_{t}\right)$ provided $K_{\mathrm{f}}$ remains constant, i.e., the absorption spectra remain unchanged. The OID phase (where $I$ or $F_{1}$ stands for fluorescence intensity at the first inflection or intermediate peak, and D stands for dip or plateau; ID is alternatively called $\mathrm{pl}$ for plateau [9]) was suggested $[10,11]$ to arise from the interplay of PS II and PS I in intact algal cells, due to the transient changes in the $\left[Q_{A}^{-}\right]$in the main pathway of photosynthesis. Furthermore, the following $D$ to $P$ ( $P$ for peak) rise reflects the net accumulation of $\left[Q_{A}^{-}\right]$as the plastoquinone pool is reduced, and, there is a 'traffic' jam in the flow of electrons all the way up to the electron acceptors of PS I [10]. Addition of the electron acceptor methyl viologen, that accepts electron from PS I, abolishes the D to P rise, but not the OID phase [10] (see Ref. 12 also). Melis [13] suggested, without proof, that the initial chloroplast fluorescence rise from $F_{0}$ to $F_{1}$ was identified as the variable fluorescence yield controlled by a type of Photosystem II center called PS II $\beta$. Graan and Ort [14] showed that the number of PS II centers capable of active water oxidation was increased by a chloroquinone 2,6-dichloro-p-benzoquinone and closely matched the number of herbicide binding sites. However, the number of PS II centers active in water oxidation was much lower when methyl-substituted benzoquinone, 2,5-dimethyl-pbenzoquinone (DMQ) was used as an electron acceptor. These experiments were explained by the hypothesis of the existence of two types of PS II center, the active and the inactive centers, the inactive centers being the ones that are ineffective in electron flow to plastoquinone and, thus, inactive in net electron flow and water oxidation. The nature of these active and inactive PS II centers has been recently examined, by independent means, in Refs. 15 and 16. In spinach thylakoids, the majority of the PS II reaction centers (68\%) recover in less than $50 \mathrm{~ms}$. However, approx. 32\% of the PS II reaction centers require a halftime of $2-3 \mathrm{~s}$ to recover. In spinach leaves, the halftime of the oxidation of $Q_{A}^{-}$ in the inactive PS II centers is $1.5 \mathrm{~s}$ [16].

In this paper, we used DCBQ and DMQ to investigate their effects on the OID phase of fluorescence transient in order to assess their relationship to the active and inactive centers, as defined earlier [14]. This has allowed us to obtain information on the nature of the OID phase that had remained controversial. We show here that DCBQ is able to quench the $F_{1}$ much more effectively than $\mathrm{DMQ}$, while $F_{0}$ remains unchanged. Since DCBQ was shown [15] to intercept electrons from the 'inactive' PS II centers, we suggest that the OID phase reflects the reduction of $Q_{A}$ to $Q_{A}^{-}$ in the inactive PS II centers. We also show that in spinach and soybean thylakoids, high temperature $\left(55^{\circ} \mathrm{C}\right.$ ) induced increase in fluorescence yield (e.g., $F_{50 \mathrm{~ms}}$, fluorescence at $50 \mathrm{~ms}$ ) is quenched differentially by the electron acceptor DCBQ and DMQ. The amplitude of $F_{50 \mathrm{~ms}}$ in $55^{\circ} \mathrm{C}$-treated samples decreases proportionally by DCBQ addition, but it is much less affected by DMQ. Thus, we suggest that the heat-induced increase in fluorescence yield is due mainly to the increase in $F_{1}$ level owing to the conversion of active PS II to inactive PS II centers. In addition, decay kinetics of $\mathrm{Q}_{\mathrm{A}}^{-}$, which is calculated from the $\mathrm{Chl} a$ fluorescence decay data, with and without DCMU after one flash is analysed in terms of a multiple exponential decay model. In the heated chloroplasts, we observed a slower decay than the normal slow component, which is suggested to reflect the back reaction between $Q_{A}^{-}$and the $S_{2}$ state. We attribute it to an additional heat effect on an inhibition of the S-state turnover in the oxygen-evolving system.

\section{Material and Methods}

Chlorolast thylakoid membranes were isolated from commercial spinach and growth chamber soybean as described $[14,17]$. Soybean plants were grown at $30^{\circ} \mathrm{C} / 20^{\circ} \mathrm{C}$ day/night temperatures and $10 \mathrm{~h} / 14 \mathrm{~h}$ day/night photoperiod. The Chl concentration of chloroplast suspension was determined by measuring absorbance at $664 \mathrm{~nm}$ and $647 \mathrm{~nm}[17,18]$.

Thylakoids were suspended in a reaction medium containing $0.4 \mathrm{M}$ sorbitol, $5 \mathrm{mM}$ Mes- $\mathrm{KOH}$ ( $\mathrm{pH} \mathrm{6.5),}$ $20 \mathrm{mM} \mathrm{KCl}, 2 \mathrm{mM} \mathrm{MgCl}$, and $1 \mu \mathrm{M}$ nigericin when fluorescence measurement was made. The $\mathrm{Chl}$ concentration was $39 \mu \mathrm{M}$. The suspension buffer for heat treatment contained $0.4 \mathrm{M}$ sorbitol, $0.5 \mathrm{mM}$ Mes- $\mathrm{KOH}$ (pH 6.5), $20 \mathrm{mM} \mathrm{KCl}$ and $2 \mathrm{mM} \mathrm{MgCl}_{2}$. The $\left(55^{\circ} \mathrm{C}\right.$ ) heat treatment time was $1 \mathrm{~min}$ for spinach thylakoids and $6 \mathrm{~min}$ for soybean thylakoids in a water-bath (Beckman, Lauda RC3) kept in the dark.

The Chl $a$ fluorescence transient was measured in a home-built spectrofluorometer [19] with modifications. The light from the exciting lamp (Kodak Carousel 4200 projector) was filtered with Corning CS 5-56 and CS 4-76 blue filters. The fluorescence was filtered with a Corning CS 2-61 red filter before it entered a monochromator set at $685 \mathrm{~nm}$ (slit widths: $4 \mathrm{~mm}$; band pass: $13.2 \mathrm{~nm}$ ). A EMI (9958 B) photomultiplier (S-20 response) was used as a photodetector. The output signal was digitized with 8 bit precision by a Biomation Model 805 waveform recorder and stored on an LSI 11 minicomputer (Digital Equipment Corporation) (see details in Ref. 19).

The kinetics of decay of variable Chl $a$ fluorescence was measured at $685 \mathrm{~nm}$ (10 nm bandwidth) by a weak measuring light. The measuring light was fired at variable times after each actinic flash. The actinic (FX-124, 
EG and $G$ ) and the measuring flashes (Stroboslave 1593A, General Radio) were filtered with Corning blue (CS 4-96) glass filters; both had a $2.5 \mu \mathrm{s}$ duration at half-maximal peak (see details in Ref. 20).

$\mathrm{Q}_{\mathrm{A}}^{-}$concentration was calculated from variable $\mathrm{Chl} a$ fluorescence according to Joliot and Joliot [21] using the formula given in Ref. 22; there is a hyperbolic relationship between the fluorescence yield $F(t)$ and the fraction $q(t)$ of closed reaction centers at time $t$ :

$\frac{F(t)-F_{\mathrm{o}}}{F_{\max }-F_{0}}=\frac{(1-p) q(t)}{1-p q(t)}$

where $F_{\max }$ is the maximum fluorescence yield when all $\mathrm{Q}_{\mathrm{A}}$ is in the reduced state, $F_{\mathrm{o}}$ is the minimum fluorescence yield when all $\mathrm{Q}_{\mathrm{A}}$ is in the oxidized state, and $p$ is the connection parameter which reflects the probability of the intersystem energy transfer from a closed unit to any other unit in the system. In this work, we assumed that the $p$ was 0.5 , as measured earlier for chloroplasts [23]. Thus, $q(t)$ could be presented explicitly as:

$q(t)=\frac{2 F_{\mathrm{v}}(t)}{F_{\mathrm{v}}^{\max }+F_{\mathrm{v}}(t)}$

where $F_{\mathrm{v}}(t)=F(t)-F_{0}$ and $F_{\mathrm{v}}^{\max }=F_{\max }-F_{0}$.

In our multiple exponential decay model, the $\mathrm{Q}_{\mathrm{A}}^{-}$ concentration at time $t, q(t)$ is given by a sum of $N$ exponential components:

$q(t)=q(0) \sum_{i=1}^{N} \alpha_{i} \exp \left(-t / \tau_{i}\right)$

where $q(0)$ is the $\mathrm{Q}_{\mathrm{A}}^{-}$concentration at time $0, \alpha_{\mathrm{i}}$ is the amplitude and $\tau_{i}$ the lifetime of the $i$ th component. The fitting of the above Eqn. 4 with the experimental data was carried out by a least-squares program using iterative method (Marquard search algorithm) [24]. Quality of fits were judged by the reduced $\chi^{2}\left(\mathrm{Ki}^{2}\right)$ criterion and the plot of the weighted difference between theoretical fit and the experimental data, normalized to the square root of the data points [25].

\section{Results}

Fig. 1 shows the $\mathrm{Chl} a$ fluorescence transients in the spinach thylakoids in the presence of different concentrations of DMQ (top graph) and DCBQ (bottom graph). In the control without exogenous quinones, the curve shows clearly the various characteristic points, namely OIDP [2-6]. I and P levels occur at $50 \mathrm{~ms}$ and 3 $s$ after the start of illumination, respectively. In both spinach and soybean (data not shown) thylakoids, increasing ( 2.5 to $20 \mu \mathrm{M}$ ) concentrations of DMQ and DCBQ affect Chl a transient differently. DMQ
A
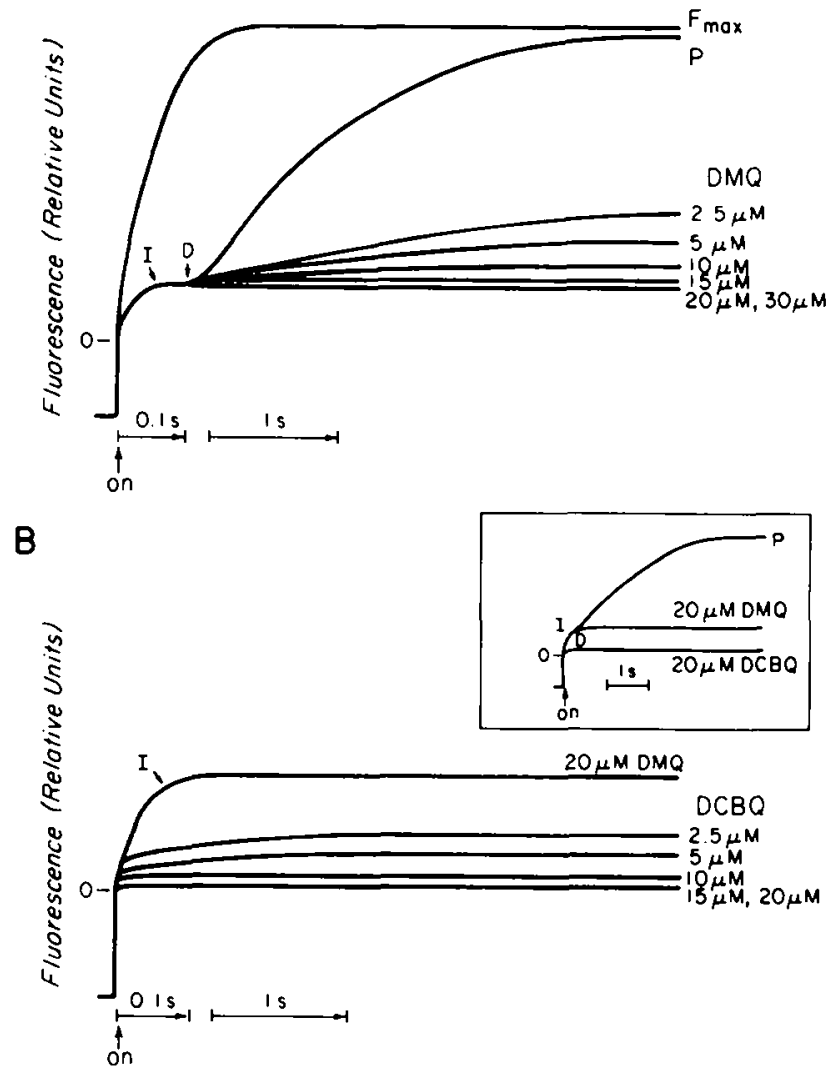

Fig. 1. Chlorophyll $a$ fluorescence transients of spinach thylakoids in the presence and absence of different concentrations of DMQ and DCBQ at $20^{\circ} \mathrm{C}$. The thylakoids were suspended in a reaction medium containing $0.4 \mathrm{M}$ sorbitol, $5 \mathrm{mM}$ Mes- $\mathrm{KOH}$ (pH 6.5), $20 \mathrm{mM} \mathrm{KCl}, 2$ $\mathrm{mM} \mathrm{MgCl}_{2}$ and $1 \mu \mathrm{M}$ nigericin. The Chl concentration was $39 \mu \mathrm{M}$. The inset shows the fluorescence transient of control and $20 \mu \mathrm{M}$ quinone-treated thylakoids. The thylakoids were dark-adapted for 10 min before the fluorescence measurement. $O$, constant fluorescence; $I$, intermediate peak fluorescence; $D$, fluorescence yield at the plateau or the dip; $P$, fluorescence yield at the peak (maximum). In (A), the fast-rising curve is with $1 \mu \mathrm{M} \mathrm{DCMU;} F_{\max }$ is the maximum fluorescence level. See list of abbreviations for the full forms of DMQ and DCBQ.

quenches only the DP rise, where $D C B Q$ is able to quench, in addition, OI phase. Fig. 2 is a plot of the dependence of the fluorescence yields at $50 \mathrm{~ms}$ and $3 \mathrm{~s}$ after the start of illumination on quinone concentration. DMQ quenches the $\mathrm{P}$ (or $F_{\mathrm{P}}$ ) level greatly, but does not affect the $I$ (or $F_{1}$ ) level (Figs. 1 and $2 \mathrm{~A}$ ). The quenching effect on $F_{\mathrm{P}}$ is saturated at $20 \mu \mathrm{M}$ DMQ. On the other hand, DCBQ not only quenches $F_{\mathrm{P}}$ but the $F_{\mathrm{I}}$ level also (Fig. 1 and Fig. 2B). This quenching effect is saturated at $15 \mu \mathrm{M} \mathrm{DCBQ}$. However, the saturated concentration of DCBQ does not affect the $O$ (or $F_{\mathrm{o}}$ ) level at all. In these calculations, the values of $F_{0}$ was obtained by the value of $F_{1}$ at $30 \mu \mathrm{M} \mathrm{DCBQ}$; this value was confirmed by measurements of $F_{0}$ by two other independent methods [6] (extrapolation of $F$, rise to 

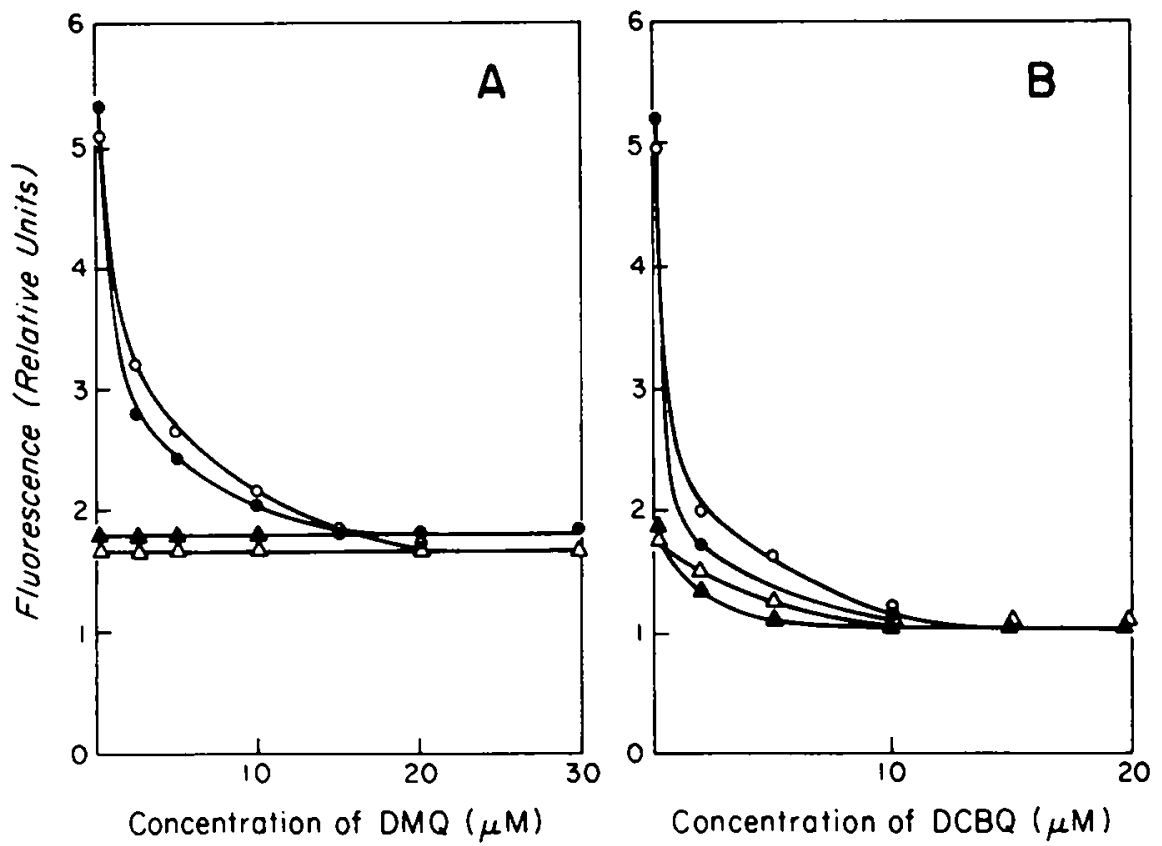

Fig. 2. Effects of increasing concentrations of DMQ (A) and DCBQ (B) on Chl a fluorescence yields at $50 \mathrm{~ms}$ and $3 \mathrm{~s}$ in thylakoid membranes Fluorescence at $50 \mathrm{~ms}(\Delta, \Delta)$ and $3 \mathrm{~s}(\bullet, 0)$ in spinach $(\Delta, \bullet)$ and soybean $(\Delta, 0)$ thylakoid membranes. $F_{0}$ level is normalized to 1 .

zero time and independence of fluorescence yield with light intensity, data not shown).

In order to quantify the quenching effect of the quinones on fluorescence yield at $50 \mathrm{~ms}\left(F_{50 \mathrm{~ms}}\right)$, the amplitude of $\left(F_{\mathrm{I}}-F_{0}\right)$ is normalized as 100 units and the quenching of fluorescence $F_{50 \mathrm{~ms}}$ by quinone is

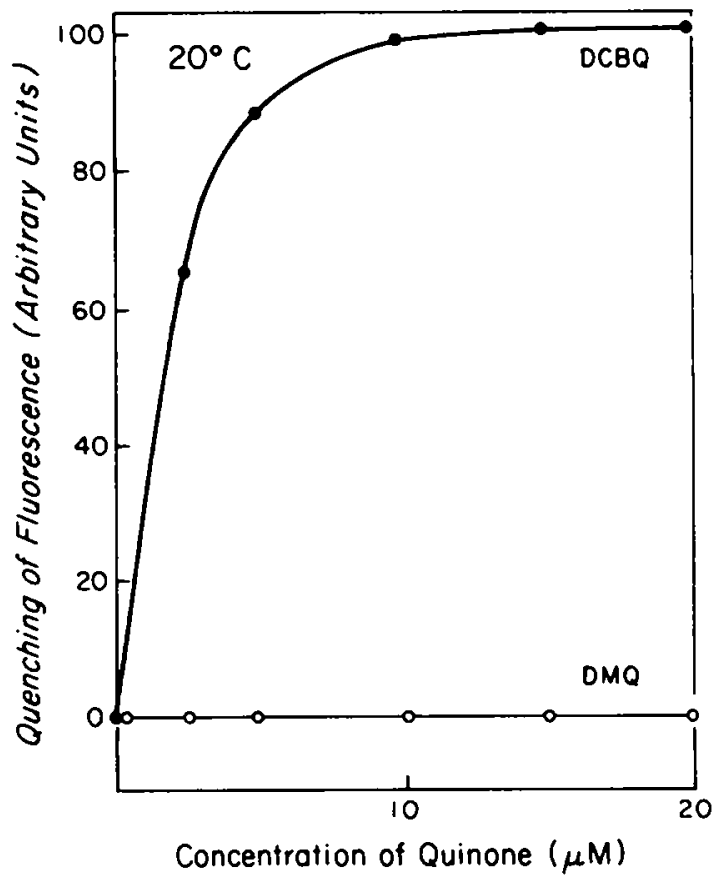

Fig. 3. Quenching of $\mathrm{Chl}$ a fluorescence at $50 \mathrm{~ms}$ by DCBQ (solid circle) and DMQ (open circle) in spinach thylakoid membranes. The amplitude difference $\left(F_{1}-F_{0}\right)$ is normalized to 100 . The quenching of fluorescence yield is the decrease in fluorescence yield from the $F_{1}$ level. calculated (Fig. 3). Quenching is absent when no exogenous quinone is added. In DCBQ treated thylakoids, the concentration of $\mathrm{DCBQ}$ at which $F_{1}-F_{0}$ is half
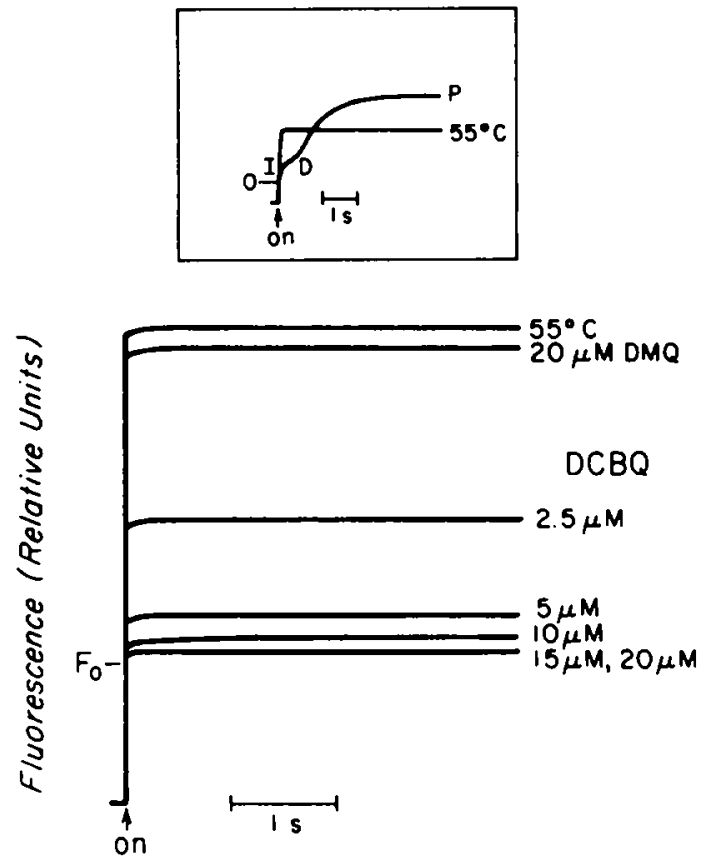

Fig. 4. Chlorophyll $a$ fluorescence transients of heat-treated thylakoid membranes of spinach and the effects of DMQ and DCBQ on the fluorescence yield. Inset (at top) shows fluorescence transients at $20^{\circ} \mathrm{C}$ and $55^{\circ} \mathrm{C}$. The thylakoid membranes were heated for $1 \mathrm{~min}$ in a medium consisting of $0.4 \mathrm{M}$ sorbitol, $5 \mathrm{mM}$ Mes- $\mathrm{KOH}$ (pH 6.5), 20 $\mathrm{mM} \mathrm{KCl}$ and $2 \mathrm{MgCl}_{2}$. Then the thylakoids were resuspended in the same medium with added $1 \mu \mathrm{M}$ nigericin when the fluorescence transient was measured at $20^{\circ} \mathrm{C}$. $F_{0}$ is the constant fluorescence yield. See the legend of Fig. 1 for other abbreviations. 


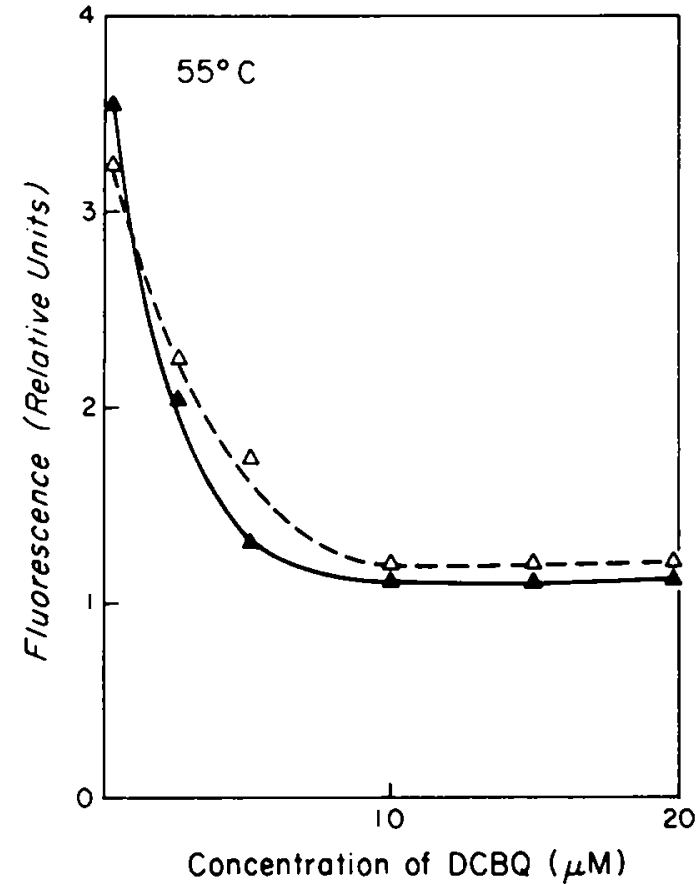

Fig. 5. Fluorescence yield at $50 \mathrm{~ms}$ as affected by DCBQ in heat-treated spinach $(\Delta)$ and soybean $(\Delta)$ thylakoid membranes. $F_{0}$ level is normalized to 1 .

quenched is $2.5 \mu \mathrm{M}$ for spinach; however, $F_{\text {soms }}$ does not decrease with increasing concentration of DMQ in the micromolar range. This concentration dependence of $F_{50 \mathrm{~ms}}$ on DCBQ is in quantitative agreement with the earlier concentration dependence data [14] on the increase in the number of PS II centers capable of wateroxidation in the presence of DCBQ in spinach thylakoids. In soybean thylakoids, $3.5 \mu \mathrm{M}$ of DCBQ is needed in order to quench $50 \%$ of the amplitude from $F_{0}$ to $F_{\mathrm{I}}$ (data not shown).

Heat treatment caused a significant change in Chl $a$ fluorescence transient in comparison to the control at $20^{\circ} \mathrm{C}$ in spinach (Fig. 4; measurements at $20^{\circ} \mathrm{C}$ ). The normal clear OID characteristic points disappeared and instead a fast rise of fluorescence yield occurred with treatment at $55^{\circ} \mathrm{C}$ (see Methods). Fig. 5 (see also Fig. 4) shows the quenching effect of DCBQ on $F_{50 \mathrm{~ms}}$ in heat-treated chloroplasts. When DCBQ was added to the heat-treated samples, we found that the heat-induced fluorescence yield declined as [DCBQ] increased and that the quenching effect of fluorescence by DCBQ is proportional to its concentration as in the thylakoids at $20^{\circ} \mathrm{C}$ (cf. with Fig. 3). However, in heat-treated samples, even 15-20 $\mu \mathrm{M}$ DCBQ could not totally quench fluorescence yield to its $F_{0}$ level as in the samples at $20^{\circ} \mathrm{C}$. These residual small increases in fluorescence yield may reflect heat-induced rise in $F_{0}$ level. Again DMQ was an ineffective quencher here (Fig. 4). Thus, based on the present data on both DCBQ and DMQ and comparison with data at $20^{\circ} \mathrm{C}$, we suggest that the increase in fluorescence yield due to heating is mainly due to the rise in ' $I$ ' level, $97 \%$ in spinach thylakoids. Soybean thylakoids give similar results (data not shown). This heat-induced rise in the ' $\mathrm{I}$ ' level is due to an increase in the inactive PS II centers. Only $5 \%$ or less of heat-induced fluorescence rise is due to increase in the ' $O$ ' level.

The top graph (A) in Fig. 6 shows the data on decays of the variable Chl $a$ fluorescence after one flash (flash 5 ) in spinach thylakoids. The first data point is at $70 \mu \mathrm{s}$. The $F_{0}$ levels used in these calculations are true $F_{0}$ levels, not the measured $F_{i}$ levels. When $10 \mu \mathrm{M}$ DCMU is added, the forward reaction of electron flow from $Q_{A}^{-}$ to $Q_{B}$ is known to be totally blocked and a slow decay of variable Chl $a$ fluorescence is observed (see curves with upside-down triangle, and in Refs. 26, 27). Heat treatment $\left(55^{\circ} \mathrm{C}, 1 \mathrm{~min}\right.$; spinach) causes an even slower decay (curve with (triangle). Furthermore, in agreement with the conclusion that $55^{\circ} \mathrm{C}$ treatment does not simply increase the ' $O$ ' level, we observed a significant

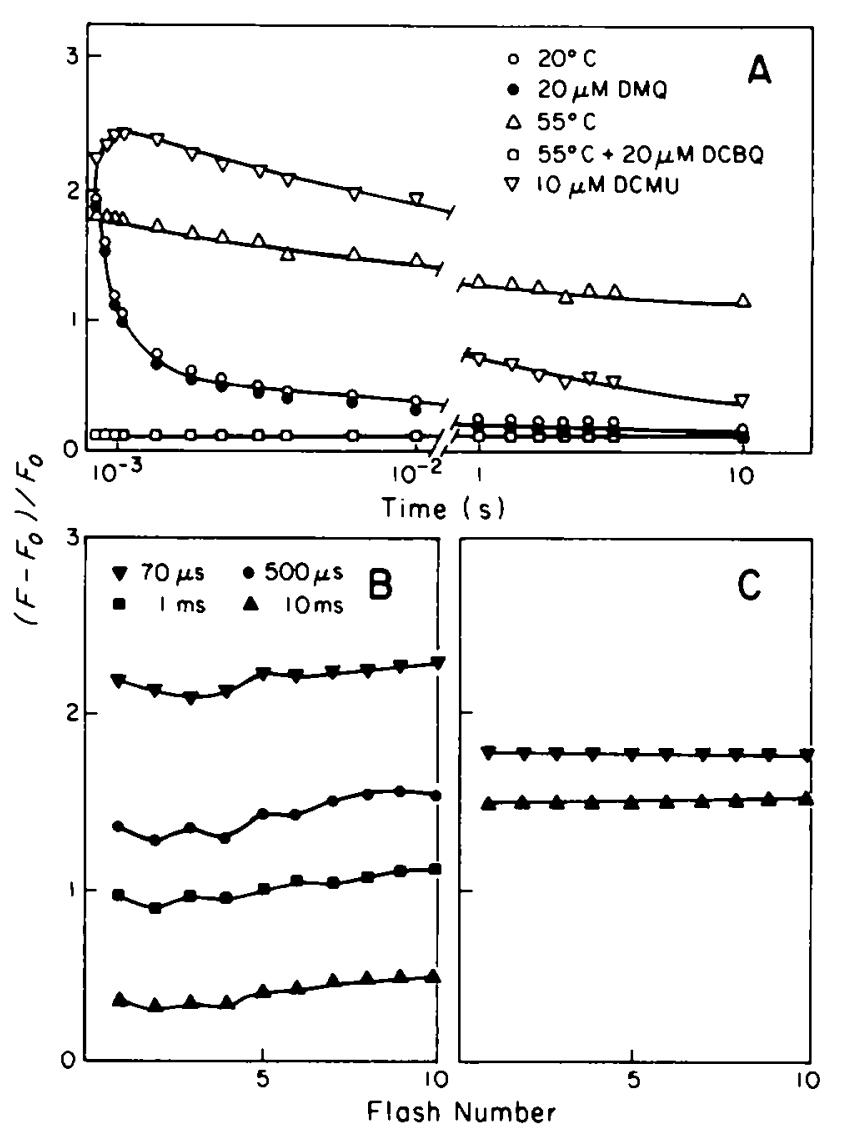

Fig. 6. Decay of variable $\mathrm{Chl} a$ fluorescence of spinach thylakoids after the fifth flash (A). Fo is the $\mathrm{Chl} a$ fluorescence yield from the measuring flash with all $\mathrm{Q}_{\mathrm{A}}$ oxidized, and $F$ is the fluorescence yield at the indicated time after the actinic flash. The actinic flash frequency was $1 \mathrm{~Hz}$. (O): $20^{\circ} \mathrm{C}$; (๑): $20 \mu \mathrm{M}$ DMQ; ( $): 55^{\circ} \mathrm{C}$; (D): $55^{\circ} \mathrm{C}+20$ $\mu \mathrm{M}$ DCBQ; ( $\nabla): 10 \mu \mathrm{M}$ DCMU. (B) Variable Chl $a$ fluorescence as a function of flash number at $20^{\circ} \mathrm{C}$; (C) Variable $\mathrm{Chl} a$ fluorescence as a function of flash number at $55^{\circ} \mathrm{C}$. The times indicated are when the measuring flash was fired. 
variable fluorescence (curves with triangle). $20 \mu \mathrm{M}$ DMQ has little effect on variable fluorescence decay at $20^{\circ} \mathrm{C}$ (cf. curves with open and closed circles) as is observed with the addition of electron acceptor methyl viologen [20]. Both abolish the DP fluorescence rise during fluorescence induction, but show no effect on fluorescence decay after an actinic flash. This is simply because the electron flow from $Q_{A}^{-}$to $Q_{B}$ is faster than the electron acceptance by these acceptors at a more distant site. However, the addition of $20 \mu \mathrm{M}$ DCBQ quenches the fluorescence level ( $t \leqslant 70 \mu \mathrm{s})$ to be close to the $F_{0}$ of the control $\left(20^{\circ} \mathrm{C}\right)$. This suggests an efficient electron acceptance by $D C B Q$ from close to the $Q_{A}^{-}$site.

The fluorescence as a function of flash number, at various times after the flash, is shown in the bottom graph (B) of Fig. 6. In a control sample $\left(20^{\circ} \mathrm{C}\right)$, a complex oscillation pattern that is superimposition of a binary oscillation (due to the operation of the two electron gate on the electron acceptor side of PS II) and an oscillation of period four (due to the turnover of the S state in the oxygen-evolving system) is observed (see, for example, Ref. 20). Heat treatment, however, damps those oscillations significantly (see Fig. 6C).

$\mathrm{Q}_{\mathrm{A}}^{-}$decay involves multiple processes (see, for example, Ref. 28). By using exponential decay models, we quantitate our results by describing the decay of $Q_{A}^{-}$in terms of three decay components representing different electron transport pathways. We realize that in reality these processes may not be necessarily independent of each other or even follow the first-order reaction. The experimentally measured $\mathrm{Chl} a$ fluorescence data were converted to $\mathrm{Q}_{\mathrm{A}}^{-}$using Eqn. 3. $\mathrm{Q}_{\mathrm{A}}^{-}$decay data as a function of time were fitted by Eqn. 3 with $N=3$ (see Material and Methods). In Fig. 7, the best fit for the three-exponential model is superimposed on the experimental decay curve in spinach thylakoids. A plot of the

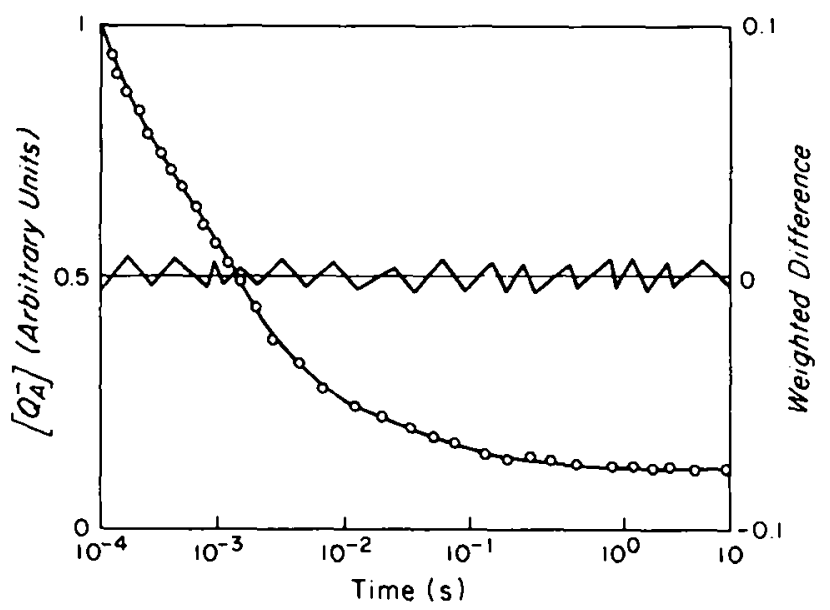

Fig. 7. The decay of the calculated $Q_{A}^{-}$concentration $(O)$ and the best fit (-) of a three exponential decay model. The weighted difference (the saw-tooth curve) is the difference between experimental data and the best fit, weighted by the square of the data points.
TABLE I

The calculated amplitude ( $\alpha$ ) and the lifetime ( $\tau$ ) of decay of $Q_{\vec{A}}$ with exponential decay models

$\mathrm{Ki}^{2}$ is the reduced chi square.

\begin{tabular}{lrcrl}
\hline & $\alpha$ & \multicolumn{1}{c}{$\tau$} & \multicolumn{1}{c}{$t_{1 / 2}{ }^{\star}$} & $\mathrm{Ki}^{2}$ \\
\hline Control & & & & \\
spinach & 0.62 & $527 \mu \mathrm{s}$ & $365 \mu \mathrm{s}$ & \\
& 0.18 & $10 \mathrm{~ms}$ & $7 \mathrm{~ms}$ & 1.1 \\
soybean & 0.20 & $2 \mathrm{~s}$ & $1.4 \mathrm{~s}$ & \\
& 0.60 & $570 \mu \mathrm{s}$ & $395 \mu \mathrm{s}$ & \\
& 0.19 & $9 \mathrm{~ms}$ & $6 \mathrm{~ms}$ & 1.2 \\
$+10 \mu \mathrm{M}$ DCMU & 0.21 & $2.5 \mathrm{~s}$ & $1.7 \mathrm{~s}$ & \\
spinach & 1.11 & $2.2 \mathrm{~s}$ & $1.5 \mathrm{~s}$ & 1.1 \\
\multirow{3}{*}{ soybean } & -0.11 & $26 \mu \mathrm{s}$ & $18 \mu \mathrm{s}$ & \\
& 1.08 & $2.3 \mathrm{~s}$ & $1.6 \mathrm{~s}$ & 1.2 \\
\hline
\end{tabular}

$t_{1 / 2}$ is the halftime; $t_{1 / 2}=\ln 2(\tau)$.

weighted difference between the experimental data and the best fit is also shown. The calculated amplitudes and halftimes are summarized in Table $I$. The residual plot and $K_{i}^{2}$ show that the best fit by a three exponential decay match the $Q_{A}^{-}$data very well and the deviations are due only to statistical noise. In both spinach and soybean thylakoids, large portion (60-62\%) of $Q_{A}^{-}$ decay is through the fast component (halftime 365-395 $\mu \mathrm{s})$. The amplitudes of the intermediate component (halftime 6-7 ms) and the slow component (halftime $1.4-1.7 \mathrm{~s})$ are $18 \%$ and $20 \%$, respectively. In DCMU treated samples, reduced $Q_{A}$ recombines with $S_{2}$ state after one actinic flash; the halftime of $Q_{A}^{-}$decay is 1.5-1.6 s. This value fits the slow component in the DCMU-free samples. In addition, an initial rise in variable fluorescence is observed in the presence of 10 $\mu \mathrm{M}$ DCMU (Fig. 6). In spinach and soybean chloroplasts, the lifetimes for the rise component are $26 \mu \mathrm{s}$ and $28 \mu \mathrm{s}$, respectively (see Table 1); its origin will be discussed later.

\section{Discussion}

A heterogeneity among PS II centers has been known for quite sometime [29]. Doschek and Kok [9] found that single first-order reaction did not fit fluorescence rise under continuous illumination in DCMU-treated chloroplasts. Melis and Homann [30,31] observed a biphasic first-order growth of area curve and identified the existence of fast-rising PS II centers, labelled as PS II $\alpha$, and slow-rising centers, labelled as PS II $\beta$. The rate of reduction of electron acceptors in PS II is about 3 -times slower in the PS II $\beta$ than in PS II $\alpha$ centers [31]. The PS II $\beta$ centers are suggested to have smaller chlorophyll antenna $[32,33]$; electron transport in these centers does not proceed via the two-electron-accumulating 
plastoquinone [34]. Although PS II $\beta$ centers may be able to oxidize water, it appears that they do so slowly $[35,36]$; thus PS II $\alpha$ centers are the dominant suorce of electrons for the reduction of NADP.

Lavergne [37] has found another heterogeneity: that of the non- $Q_{B}$ (or $B$ ) centers; these are impaired at the $Q_{B}$ site and they do not transfer electrons efficiently to the plastoquinone pool. These may be considered inactive PS II centers. Lavergne [38] showed that these non- $\mathrm{Q}_{\mathrm{B}}$ centers can be induced to turnover by exogenous quinone, although neither di- nor tetramethylquinone seemed to fully relieve the acceptor side limitation. As noted earlier, Graan and Ort [14] showed that micromolar concentrations of a chloroquinone DCBQ can support flash-induced water oxidation in what they called inactive PS II centers much more effectively than DMQ. From our $\mathrm{Chl} a$ fluorescence transient experiments (Fig. 1-3), done under similar experimental conditions, we found that $\mathrm{DCBQ}$ is much more effective than DMQ in quenching the ID $\left(F_{1}\right)$ fluorescence level. The absence of any effect of DCBQ on true $F_{0}$ indicates that the observed quencing is due to a diminished $\mathrm{Q}_{\mathrm{A}}^{-}$ concentration, but not due to nonphotochemical quenching.

Based on the differential effects of micromolar concentrations of electron acceptors DMQ and DCBQ on $F_{1}$ quenching (Figs. 1 and 2 ), we suggest that OID phase reflects the reduction of the electron acceptor $Q_{A}$ to $Q_{A}^{-}$in the inactive PS II centers. An earlier study by Melis [13] on the quenching of fluorescence rise $\left(F_{0}\right.$ to $F_{1}$ ) was done by adding 100-200 $\mu \mathrm{M}$ DMQ and TMQ to spinach thylakoids. The interpretation given was that the initial fluorescence rise from $F_{0}$ to $F_{\mathrm{I}}$ is due to the prompt reduction of the primary electron acceptor $Q_{A}$ of PS II $\beta$ and the consequence of the inability of PS II $\beta$ to donate electron, on a fast scale, to secondary electron acceptors. Although this interpretation is apparently similar to that given in this paper, it is based on the use of high concentrations of quinones that affect the $F_{0}$ level as well and is not based on the differential effects of low $(\mu \mathrm{M})$ quinones $\mathrm{DCBQ}$ and $\mathrm{DMQ}$ on inactive and active centers, respectively. Our results in this paper justify our conclusions, but those in the earlier paper [13] do not. Furthermore, it is not clear whether the inactive centers are identical to PS II $\beta$ centers $[30,31]$. Inactive PS II centers are defined by the interaction between $Q_{A}$ and the PQ pool, whereas PS II $\beta$ centers are defined by their antenna size. Thus, they represent two different criteria for classifying PS II centers [16]. A recent work [39] suggests that PS II $\beta$ centers exist in both active and inactive forms. Thus, it is equally likely that PS II $\alpha$ centers also exist in inactive and active forms.

Schreiber and Armond [40] measured heat-induced (up to $60^{\circ} \mathrm{C}$ ) changes of $\mathrm{Chl}$ fluorescence in Larrea divaricata chloroplasts and observed the $F_{0}$ level to rise greater than 3-fold from that at $25^{\circ} \mathrm{C}$; a concomitant $F_{\max }$ decline was also observed. It was postulated that heat-induced increase in $F_{0}$ reflects inhibition of energy conversion at system II centers, which may be caused by a functional separation of the electron acceptor $Q_{A}$ from the primary electron donor P680. This implies that $K_{\mathrm{p}}\left[\mathrm{Q}_{\mathrm{A}}\right]$ in Eqn. 1 that is maximum at $F_{0}$ is no longer maximum; furthermore, this increase in fluorescence could also be due to decrease in $K_{1}$ due to other physical changes. Sane et al. [41] suggested that heating causes an increase in excitation energy transfer $\left(K_{t}\right)$ from PS II to PS I, or a change from the 'state I' to 'state II' (see Ref. 42); this, however, would explain the decline in fluorescence. Weis [43] observed almost parallel decline of variable fluorescence, $F_{v}$, and rise of $F_{0}$ versus temperature by measuring $\mathrm{Chl}$ fluorescence transient in heat-pretreated spinach thylakoids. $F_{0}$ rise at above $50^{\circ} \mathrm{C}$ was 3-4-fold. Sundby et al. [44] concluded that at $30^{\circ} \mathrm{C}$ there were $30 \%$ PS II $\beta$ and 70\% PS Il $\alpha$ centers, whereas at $45^{\circ} \mathrm{C}$, as much as $84 \%$ of centers were PS II $\beta$.

Based on the Chl $a$ fluorescence transient in the absence of PS II inhibitor (Figs. 4,5), our results show that $F_{50 \mathrm{~ms}}$ rise in heat-treated thylakoids can be diminished by $15-20 \mu \mathrm{M}$ of DCBQ, while only small quenching was obtained by $20 \mu \mathrm{M}$ DMQ under our experimental conditions. In this work, we have shown that $20 \mu \mathrm{M}$ DMQ is able to quench $F_{\mathrm{p}}$ to $F_{1}$, while 20 $\mu M$ DCBQ quenches $F_{p}$ to $F_{o}$ (Figs. 1 and 2). Thus, the fluorescence yield differences between the effects of 20 $\mu \mathrm{M}$ DMQ and $20 \mu \mathrm{M}$ DCBQ could be attributed mainly to heat-induced rise in the amplitude of $F_{0}$ to $F_{1}$. Only a minor change occurs in the $F_{0}$ level upon heat treatment, in contrast to data in Refs. 40 and 43 . This residual small effect, however, could be interpreted by changes in excitation energy transfer [40]. The differential effect of quinones DCBQ and DMQ on heatinduced fluorescence rise leads us to suggest that the significant increase of fluorescence in heat-treated thylakoids is on $F_{1}$ level, not $F_{0}$ level. Thermal conversion from active PS II centers to inactive PS II centers increases $F_{1}$ level, as expected from our interpretation of the OID phase. DCBQ is able to draw electrons from inactive PS II centers and therefore is able to quench heat-induced fluorescence rise, while DMQ is less effective. The increase in $F_{\mathrm{L}}$ level is accompanied by a dramatic decrease in the rate of $\mathrm{O}_{2}$ evolution (cf. Ref. 45). The small quenching by $20 \mu \mathrm{M}$ DMQ may be due to the absence of most of the active PS II centers (Fig. 4).

From freeze-fracture studies, Gounaris et al. [46,47] showed reorganization of the thylakoid membrane at moderately elevated temperatures. Sundby et al. [44] found that above $30^{\circ} \mathrm{C}$ there is a disassociation of peripheral light-harvesting $\mathrm{Chl} a / b$ complex (LHC II) from PS II and a migration of LHC II to the PS-I-rich 
non-appressed thylakoid regions. We speculate that the heat-induced reorganization of thylakoid membranes may also alter the reaction center II (D1 and D2 protein) comformation and, thus, the previously active PS II centers cannot perform efficient electron transfer from $\mathrm{Q}_{\mathrm{A}}^{-}$to the plastoquinone pool. Those centers, therefore, would act like inactive PS II centers in which electron transfer to plastoquinone pool is impaired and a quick rise in initial fluorescence would occur as in the DCMU-inhibited PS II centers.

After one flash, the initial first order component of variable $\mathrm{Chl} a$ fluorescence reflects electron flow from $Q_{A}^{-}$to $Q_{B}$ in reaction centers which have $Q_{B}$ bound before the flash [28]. In spinach chloroplasts, the halftime of the fast component is $320 \mu \mathrm{s}$ at $\mathrm{pH} 6.5$ [21]. In our samples at $\mathrm{pH} 6.5$, halftimes of this component are almost the same: $365 \mu \mathrm{s}$ for spinach and $395 \mu$ s for soybean, respectively. The intermediate component has a halftime of 6-7 ms. This time may reflect the process of movement of plastoquinone molecules from the plastoquinone pool to the reaction centers which have no $Q_{B}$ bound in the dark [28]. The third component, the slow component, is suggested to reflect the back-reaction between $Q_{A}^{-}$and the $S_{2}$ state of the oxygen evolving complex, since its halftime matches that of $Q_{A}^{-}$ decay in the presence of DCMU [48] (Table I). It has been known from Bennoun's work [26] that the reoxidation of the acceptor $Q_{A}^{-}$after an illumination in the presence of DCMU is a recombination between it and $\mathrm{S}_{2}$, one of the redox states of the oxygen evolving complex. In the presence of $10 \mu \mathrm{M} D C M U Q_{A}^{-}$is oxidized with a halftime of $1.5 \mathrm{~s}$ after one flash [27]. This back reaction is $\mathrm{pH}$-dependent. At $\mathrm{pH} \mathrm{6.5,} \mathrm{the}$ time at which $\left[Q_{A}\right]$ is $50 \%$ of the maximum $Q_{A}^{-}$for $S_{2}$ and $\mathrm{Q}_{\mathrm{A}}^{-}$back-reaction is $1.3 \mathrm{~s}$ and at $\mathrm{pH} 7.5$ it is $2 \mathrm{~s}$ [48]. Results in this paper are in agreement with those mentioned above (see Table I).

In the DCMU-treated thylakoid membranes, an initial rise in variable Chl $a$ lfluorescence is observed (Fig. 6) before it declines. This rise component corresponds to a process with a lifetime of about $26 \mu \mathrm{s}$ in spinach. This can be compared with an increase of $F_{\mathrm{v}}$ with a halftime of $50 \mu \mathrm{s}$ [49] and of $250 \mu \mathrm{s}$ range [50]. This was suggested to reflect the re-reduction of the oxidized reaction center $\mathrm{P}_{680}^{+}$; the observed times were related to the equilibration of electrons on the donor side of PS II $[49,50]$. The reduction of $\mathrm{P}_{680}^{+}$follows multiphasic kinetics [51]. Eckert and Renger [52] measured the relaxation of absorption changes at $820 \mathrm{~nm}$ versus time, which reflects the $\mathrm{P}_{680}^{+}$reduction kinetics. They found three decay components of lifetimes $20 \mathrm{~ns}, 330 \mathrm{~ns}$ and $>1.4$ $\mu \mathrm{s}$ after the first saturating flash. It has been known that the inhibition of $Q_{A}^{-}$reoxidation by $Q_{B}$ at low temperature [52], or in the presence of DCMU [53] alters the kinetics of $\mathrm{P}_{680}^{+}$decay. In order to explain the $F_{\mathrm{v}}$ rise with $26 \mu$ s lifetime in the presence of DCMU in this work, we assume that the effect of blockage of electron transport between $Q_{A}^{-}$and $Q_{B}$ by $D C M U$ is to decrease the fast components in the nanosecond range and increase the slow component in the microsecond range for $\mathrm{P}_{680}^{+}$decay; the halftime values of the slow component(s) in the microsecond range varies in the literature [52-54]. It is also considered likely that the 26-28 $\mu \mathrm{s}$ rise component observed in our work may originate in the recombination of $\mathrm{Q}_{\mathrm{A}}^{-}$with $\mathrm{P}_{680}^{+}$; if so, we will have to postulate that the $\mathrm{Chl} a$ fluorescence yield in the presence of $\mathrm{P}_{680}^{+} \mathrm{Q}_{\mathrm{A}}^{-}$is smaller than in the presence of $\mathrm{P}_{680} \mathrm{Q}_{\mathrm{A}}$.

Chylla and Whitmarsh [16] showed that in spinach leaves, oxidation of $\mathrm{Q}_{\mathrm{A}}^{-}$, monitored by fluorescence induction measurement, displays a halftime of about 1.5 $\mathrm{s}$, which matches the halftime of the recombination between $Q_{A}^{-}$and $S_{2}$ state. As a result, one could speculate that the major decay pathway of $\mathrm{Q}_{\mathrm{A}}^{-}$in the inactive PS II centers may be through the recombination between $Q_{A}^{-}$and the $S_{2}$ state. Since, as we have shown, heat alters the ratio of the active PS II centers to inactive PS II centers, it is expected that a larger portion of $\mathrm{Q}_{\mathrm{A}}^{-}$may be oxidized through this back reaction route in heated samples. A slow decay of $Q_{A}^{-}$is indeed observed (Fig. 6). This reaction is further slowed in heat-treated samples, because of additional heat-induced effects (cf. Refs. 43, 45, 55).

During the revision of this paper, we became aware of independent measurements of Bukhov et al. [56] in heat-treated Amaranthus chloroplasts in which preheating was suggested to shift the redox state of $Q_{A}$ in weak light.

\section{Acknowledgements}

This study was supported by the Interdisciplinary McKnight Grant to the University of Illinois at Urbana-Champaign. We are thankful to Drs. Don Ort and John Whitmarsh for support during our studies.

\section{References}

1 Kautsky, H. and Hirsch, A. (1931) Naturwissenschaften, 48, 964.

2 Govindjee and Papageorgiou, G. (1971) in Photophysiology (Giese, A.C., ed.), Vol. 6, pp. 1-64, Academic Press, New York.

3 papageorgiou, G. (1975) in Bioenergetics of Photosynthesis (Govindjee, ed.), pp. 319-366, Academic Press, New York.

4 Lavorel, J. and Etienne, A.L. (1977) in Primary Processes of Photosynthesis (Barber, J., ed.), pp. 203-268, Elsevier/NorthHolland Bromedical Press. Amsterdam.

5 Govindjee, Amesz, J. and Fork, D.C. (eds.) (1986) Light Emission by Plants and Bacteria, see pp. 62-65; 478-482; 519-526; 542; 546-577; 590-596; 602-614, Academic Press, Orlando.

6 Govindjee and Satoh, K. (1987) in Light Emission by Plants and Bacteria (Govindjee, Amesz, J. and Fork, D.C., eds.), pp. 497-538, Academic Press, Orlando.

7 Wong, D. and Govindjee (1979) FEBS Lett. 97, 373-377. 
8 Briantais, J.M., Vernotte, G., Krause, G.H. and Weis, E. (1986) in Light Emission by Plants and Bacteria (Govindjee, Amesz. J. and Fork, D.C., eds.), pp. 539-587, Academic Press, Orlando.

9 Doschek, W.W. and Kok, B. (1972) Biophys. J. 12, 832-838

10 Munday Jr. J.C. and Govindjee (1969) Biophys. J. 9, 1-21.

11 Schreiber, U. and Vidaver, W. (1974) Biochim. Biophys. Acta 368. 97-102.

12 Lavergne, J. (1974) Photochem. Photobiol. 20, 377-386.

13 Melis, A. (1985) Biochim. Biophys. Acta 808, 334-342.

14 Graan, T. and Ort, D.R. (1986) Biochim. Biophys. Acta 852, 320-330.

15 Chylla, R.A., Garab, G. and Whitmarsh, J. (1987) Biochim. Biophys. Acta 894, 562-511.

16 Chylla, R.A. and Whitmarsh, J. (1989) Plant Physiol. 90. 765-772.

17 Graan, T. and Ort, D.R. (1984) J. Biol. Chem. 259, 14003-14010.

18 Ziegler, R. and Egle, K. (1965) Beitr. Biol. Pflanz. 41, 11-37.

19 Blubaugh, D.J. and Govindjee (1988) Plant Physiol. 88, 1021-1025.

20 Eaton-Rye, J.J. and Govindjee (1988) Biochim. Biophys. Acta 935, 248-257.

21 Joliot, A. and Joliot, P. (1964) C.R. Acad. Sci. Paris 258, 4622-4625.

22 Mathis, P. and Paillotin, G. (1981) in The Biochemistry of Plants: Photosynthesis (Hatch, M.D. and Boardman, N.K., eds.), Vol. 8 pp. 97-161, Academic Press, Sydney.

23 Forbush, B. and Kok, B. (1968) Biochim. Biophys. Acta 162 , 243-253.

24 Grinvald, A. and Steinberg, I.Z. (1974) Anal. Biochem. 59 583-598.

25 Haehnel, W., Holzwarth, A.R. and Wendler, J. (1983) Photochem. Photobiol. 37, 435-443.

26 Bennoun, P. (1970) Biochim. Biophys. Acta 216, 357-363.

27 Robinson, H.H. and Crofts, A.R. (1983) FEBS Lett. 153, 221-226.

28 Crofts, A.R., Robinson, H.H. and Snozzi, M. (1984) in Advances in Photosynthesis Research (Sybesma, C., ed.), Vol. 1, pp. 461-468, Martinus Nijhoff, Dordrecht.

29 Black, M.T., Brearley, T.H. and Horton, R. (1986) Photosyn. Res. 8, 193-207.

30 Melis, A. and Homann, P.H. (1975) Photochem. Photobiol. 21, 431-437.

31 Melis, A. and Homann, P.H. (1976) Photochem. Photobiol. 23, 343-350.

32 Melis, A. and Homann, P.H. (1978) Arch. Biochem. Biophys. 190 , 523-530.

33 Melis, A. and Duysens, L.N.M. (1979) Photochem. Photobiol. 29 , 373-382.
34 Thielen, A.P.G.M. and Van Gorkom, H.J. (1981) FEBS Lett. 129, 205-209.

35 Melis, A. (1985) Biochim. Biophys. Acta 808, 334-342.

36 Thielen. A.P.G.M. and Van Gorkom, H.J. (1981) in Photosynthesis II. (Akoyunoglou, G., ed.), pp. 57-64, Balaban International Science Service, Philadelphia, PA.

37 Lavergne. J. (1982) Photobiochem. Photobiophys. 3, 272-285.

38 Lavergne, J. (1982) Biochim. Biophys. Acta 682, 345-353.

39 Guenthe, J.E., Nemson, J.A. and Melis, A. (1988) Biochim. Biophys. Acta 934, 108-117.

40 Schreiber, U. and Armond, P.A. (1978) Biochim. Biophys. Acta 502. 138-151.

41 Sane, P.V., Desai, T.S., Tatake, V.G. and Govindjee (1984) Photosynthetica $18,439-444$.

42 Fork, D.C. and Satoh, K. (1986) Annu. Rev. Plant Physiol. 37, 335-361.

43 Weis, E. (1982) Plant Physiol. 70, 1530-1534.

44 Sundby, C., Melis, A., Maenpaa, P. and Andersson, B. (1986) Biochim. Biophys. Acta 851, 475-483.

45 Cheniae. G. and Martin, I. (1966) Brookhaven Symp. Biol. 19 $409-417$.

46 Gounaris, K., Brain, A.P., Quinn, P.J. and Williams, W.P. (1983) FEBS Lett. 153, 47-52.

47 Gounaris, K., Brain. A.P., Quinn, P.J. and Wiliams, W.P. (1984) Biochim. Biophys. Acta 766, 198-208.

48 Eaton-Rye, J. and Govindjee (1988) Biochim. Biophys. Acta 935 , 237-247.

49 Robinson, H. and Crofts, A. (1987) Progr. Photosynth. Res. 2 , 429-432.

$50 \mathrm{Xu}$, C., Rogers, S.M.D., Goldstein, C., Widholm, J.M. and Govindjee (1989) Photosyn. Res. 21, 93-106.

51 Wydrzynski, T.J. (1982) in Photosynthesis, Vol. I (Govindjee, ed.), pp. 469-506, Academic Press. New York.

52 Eckert, H.-J. and Renger. G. (1988) FEBS Lett. 236, 425-431.

53 Renger. G. and Wolff, C.H. (1976) Biochim. Biophys. Acta 423 , 610-614.

54 Sonneveld, A., Rademaker, H. and Duysens, L.N.M. (1979) Biochim. Biophys. Acta 548, 536-551.

55 Coleman, W.J., Govindjee and Gutowsky, H.S. (1988) Photosyn. Res. 16, 251-276.

56 Bukhov, N.G., Sabat, S.C. and Mohanty, P. (1989) Photosyn. Res. in press. 